\title{
Optimizing Natural Light Distribution for Indoor Plant Growth Using PMMA Optical Fiber: Simulation and Empirical Study
}

\author{
Bahram Asiabanpour (D), Alejandra Estrada, Ricardo Ramirez, and Marisa S. Downey \\ Ingram School of Engineering, Texas State University, San Marcos, TX, USA \\ Correspondence should be addressed to Bahram Asiabanpour; ba13@txstate.edu
}

Received 9 October 2017; Revised 25 March 2018; Accepted 26 April 2018; Published 3 June 2018

Academic Editor: Onder Ozgener

Copyright (C) 2018 Bahram Asiabanpour et al. This is an open access article distributed under the Creative Commons Attribution License, which permits unrestricted use, distribution, and reproduction in any medium, provided the original work is properly cited.

Daylighting methods have evolved along with the impetus to reduce the total nonrenewable utility energy consumed by lighting. In general, daylighting systems are an efficient method of delivering light for indoor applications. However, there is little research looking specifically at indoor agriculture applications. Today, optical fibers are commonly used in various applications including imaging, lighting, and sensing. Our study simulated and tested the efficiency of an optical fiber daylighting system in an indoor environment. We tested the illumination performance of optical fibers and specifically looked at light intensity, light uniformity, and the spectrum of $20 \mathrm{~mm}$ and $3 \mathrm{~mm}$ optical fibers at five distances by offsetting a spectrometer. The scenarios were first modeled and tested using lighting simulation software. Similar settings were then empirically implemented and measured. The results showed that a difference in diameter had an effect on light intensity and light uniformity; the larger the diameter the better the light uniformity and light intensity. Further, the distance at which the spectrometer was placed in reference to the light source showed a relationship between both light intensity and light uniformity; the smaller the distance the more the intensity and the less the uniformity. Additionally, the experiments showed that sunlight intensity was 30 times and 140 times greater than optical fiber output intensity in the absence of any UV filter and presence of UV light, respectively.

\section{Introduction}

1.1. The Importance of Energy in Agriculture. The global population is currently 7.4 billion according to the United States Census Bureau [1] and is expected to increase to 9 billion by the year 2050. Meanwhile, food production is predicted to decrease [2]. Agriculture occupies $38 \%$ of the Earth's surface and is the largest amount of land dedicated to a single purpose [3]. Unfortunately, agriculture is also believed to be the main cause of climate change, biodiversity loss, and degradation of land and fresh water [2]. Thus, it is important to consider other methods of plant cultivation to maintain the environment and support global population growth.

The impetus for growing crops indoors is the ability to achieve high yields of quality nutrients. The use of greenhouses (GH), vertical farms (VFs), aquaponics, hydroponics, and other plant growing methods have thus been studied and implemented over the years. Greenhouses are a centuries-old concept where plants are placed in a structure where the light of the sun can pass through transparent panels to provide adequate light to support growth without being susceptible to the uncontrollable effects of nature.

There is an interest in greenhouses because arable portions of the world are scarce. Greenhouses often supplement natural light with artificial light to increase yields [4]. Additionally, greenhouses support the growing consumer interest in locally sourced foods. Sales of locally grown fruits and vegetables are growing at a rate of $20 \%$; thus GHs and VFs are in high demand. A profitability comparison of GHs and VFs indicates that there is a slight economic preference toward the VF [4]. The electricity usage for lighting a VF outweighs a $\mathrm{GH}$, but that is negated by high consumption of electricity for GH heating, ventilation, and air conditioning (HVAC) [4]. A reduction in utility energy requirements for artificial lighting in a VF model reduces operating expenditures and would create an appealing business proposition.

Operating an indoor agricultural business continues to be a challenge. In one study, a hypothetical evaluation was done 
on the impact of artificial lighting on a vertical farm, and it was concluded that a $100,000 \mathrm{~m}^{2}(100 \mathrm{~m} \times 100 \mathrm{~m} \times 10$ levels $)$ facility would require $133,585,200 \mathrm{kWh}$, which is an enormous amount of light and highlights energy consumption as a limiting factor on operational sustainability [2]. The amount of energy needed to support plant growth through artificial light is substantial, especially when done at scale. Adding to these challenges is the desire to reduce overall energy use in buildings. In 2010, the US Department of Energy reported an energy consumption of $40 \%$ for commercial and residential buildings (Buildings Energy Data Book, 2010). As a result, there is a desire to reduce energy consumption due to artificial lighting in buildings [5]

Despite such challenges, the trends in agricultural suggest that indoor or urban farming will continue to gain traction in the United States and other countries. Over the next five years, the planned expansion range is 8 to 16 million square feet [6]. And while artificial light is becoming a popular choice for increasing and sustaining yields in greenhouses and vertical farms, photosynthesis is still most optimal with natural light [7]. A comparison of artificial and natural light for photosynthesis suggested that using artificial light is largely inefficient [7]. Thus, it is necessary to address both economic and plant growth challenges in the use of artificial light. Importantly, novel daylighting methods may reduce energy consumption and costs.

1.2. Daylighting Systems. There are various natural lighting methods being used for indoor illumination, which offset artificial light to reduce energy consumption. Daylighting is a method used for delivering natural light inside a building through an opening to complement artificial lighting [8]. This method is a strategy often used in both modern and ancient architecture and can reduce the energy consumption in buildings associated with artificial lighting with the additional benefit of visual comfort [8].

Popular commercialized daylighting systems include heliostats, solar tubes, and skylights. The heliostat system can transmit natural light using an array of mirrors that track the sun to reflect the light into a building [9]. A fenestration located on the roof allows light to pass through and defines a skylight feature. Sundolier is an innovative skylight system that uses sun-tracking to collect and concentrate sunlight inside a building [9]. Another commercially available daylighting system is a light pipe, also known as a solar tube. The light pipe is composed of a dome, which collects the sunlight, and a guide made of reflective material allowing light transmission into the interior of a building where a diffuser is placed at its output for distribution [10].

The efficiency of converting photovoltaic energy back into visible radiation is less than one percent, while the unconverted use of the solar radiation in the visible range is reported to be $50 \%$ [11]. One ingenious way that natural light has been directed inside a building without energy conversion is through optical fiber. Optical fiber daylighting systems (OFDs) are a combination of a solar collector that is either active or passive that is coupled to optical fibers that are either polymer or silica for transmission deep into the interior of a building. A Japanese OFD system named Himawari concentrates and collects sunlight by utilizing multiple Fresnel lenses and sun-tracking and then distributes that light into buildings using optical fiber [9].

In general, optical fiber daylighting systems utilize optical fibers as a light delivery method. Concentrated light moves through the optical fibers and is then delivered to the point of use. A subset of an OFD system is the hybrid lighting system (HLS) which encompasses the OFD architecture by appending artificial light to support consistent lighting levels through controlled dimming [12]. Echy [13], Parans [14], and Sollektor [15] provide commercial HLS systems. Optical fiber technology is a major factor in the adoption of the OFD framework. According to Kröplin et al. [16], plastic optical fibers (POFs) offer many advantages over glass optical fibers (GOFs) for illumination purposes due to lower cost, flexibility, and safety aspects such as emergency lighting. Koike and Asai [17] have addressed the future of plastic optical fiber while different researchers have investigated plastic optical fiber experimentally (Garito et al. [18], Ishikawa et al. [19], Yanhua et al. [20], Numata et al. [21], and Awetehagn et al. [22]).

1.3. Photosynthetic Active Radiation. Photosynthetic active radiation (PAR) is the electromagnetic radiation that plants use for photosynthesis over the $400 \mathrm{~nm}$ to $700 \mathrm{~nm}$ spectra. The unit of measurement is called the photosynthetic photon flux density (PPFD) and is defined as micromoles per square meter per second $\left(\mu \mathrm{mol} / \mathrm{m}^{2} / \mathrm{s}\right)$. According to the StarkEinstein law every photon (quantum) that is absorbed will excite one electron. Plants contain pigments that have an affinity to photons of particular wavelengths, and photons of a particular wavelength have different energy levels. Therefore, the spectral absorptance of the plant plays a critical role as to whether the measured PPFD value is effective in photosynthesis.

An energy weighted curve was obtained through experimental results by averaging spectral absorptance and photosynthetic rates in 22 chamber grown crops [23]. If the Plank relationship $(E=h c / \lambda)$ is applied to the energy weighted curve the quantum weighted curve can be generated. In general, the spectrum of the light source is necessary to evaluate the impact on photosynthesis. With that said, however, the light spectrum for plants is not fully understood. One study indicated that commercial PAR sensors contain filters that reduce the yield photon flux by approximately 30\% [2]. The work of McCree influenced the filter specifications. Each plant or crop will have its own PAR preference, but the $\mathrm{McCree}$ curve is a great resource to generate a baseline in the design of a variable indoor grow room.

1.4. Research Focus. This study assessed the light distribution (i.e., uniformity and intensity) of poly(methyl methacrylate) (PMMA) optical fiber at two different diameters $(3 \mathrm{~mm}$ and $20 \mathrm{~mm}$ ). The role played by the distance between the end effector (i.e., light crystal connected to the end of the fiber optics cable) and the surface of the use (i.e., plants) in terms of light distribution and uniformity and intensity 
was also studied. Finally, the intensity and quality of direct sunlight and delivered sunlight through the optical cables were studied.

\section{Method}

This study utilized both simulation and empirical methods. Both methods utilize two different PMMA optical fiber sizes $(2 \times 3 \mathrm{~mm}$ and $20 \mathrm{~mm})$ at five different heights $(6,8,10,12$, and 14 in) to determine the effect of height on both light intensity and light uniformity. To provide a consistent light source, an artificial light was utilized.

\subsection{Simulation Modeling}

2.1.1. End Glow Design Using Light Modeling. The designs for both the passive $20 \mathrm{~mm}$ and the $2 \times 3 \mathrm{~mm}$ (using two fiber optics cables with a diameter of $3 \mathrm{~mm}$ for each) daylighting systems were modeled and simulated using AGI32 light design simulation software [24]. The different functions of AGI32 allow a study of light intensity and distribution for indoor and outdoor applications. AGI32 provides a numerical point-by-point calculation for where luminaries are placed on any surface and then evaluates its distribution in any simulated environment This software is commonly used to design various architectural and building lighting systems. The use of this software for our research is considered a nontraditional use and has been implemented in very few studies. One such study was the optimization of a heater for additive manufacturing systems [25-27]. AGI32 was utilized to determine and compare the collected data on the light uniformity and light intensity for both diameters and height levels.

2.1.2. Modeling. The modeling of $6 \mathrm{~mm}$ and $20 \mathrm{~mm}$ fiber optics cables was conducted in a volume similar to a plant growth rack (i.e., 90 in $\times 24$ in $\times 18$ in). In the model, the fiber optics diameters were set to $20 \mathrm{~mm}$ and $6 \mathrm{~mm}$ (to resemble the use of two $3 \mathrm{~mm}$ cables). The lux of the light was determined based on the measurement of the artificial light source passing through each of the cables and was measured at about 1,000 lux. The light placement was conducted for five different height levels: 6, 8, 10, 12, and 14 inches.

\subsection{Empirical Study}

2.2.1. Subsystems. The empirical study included the development of electrical (halogen lamp), mechanical (rack), and optical (cables and crystal end effectors) subsystems (see Figure 1) as well as designs of the experiment to reference $2 \times$ $3 \mathrm{~mm}$ and $20 \mathrm{~mm}$ fiber optics cables. Some of the components were either fabricated or purchased for implementation of this light delivery system.

\subsubsection{Sampling Procedure and Experimental Manipulations.} To obtain a consistent result, instead of natural light, a single halogen lamp with a light intensity of 32,000 lux at 4 in. away from the light surface was used to emit light into a

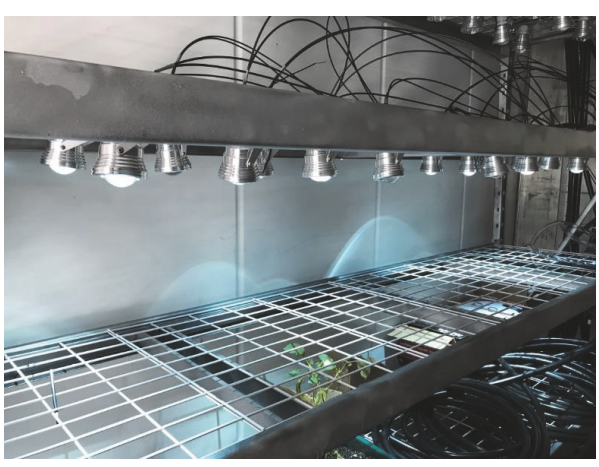

Figure 1: Components of the electrical, optical, and mechanical subsystems for the study.

group of bundled fiber optics cables. The use of artificial light was important in order to determine the light intensity and light uniformity from consistent light propagation. A light spectrometer (Sekonic C-7000) was used to measure the emitted light illuminating out of the end effector of each cable with predefined distances $(6,8,10,12$, and 14 in). Similar to the simulation study, a total of 10 runs (two cables $\times 5$ distances) were measured.

2.3. Natural Light Empirical Study. An experiment was performed to compare the performance between two $20 \mathrm{~mm}$ optical fibers with and without an UV filter. The referenced UV filter was located outside of the building and coupled at the input of the optical fiber where the sun would be in direct contact. The delimiters in the experiment were that there was a diffuser at the end of the optical fiber that contained a lens component that was not evaluated and the losses due to coiling of the optical fiber during routing. Two optical fibers spanning 54 feet were mounted exterior to a storage container and routed to the interior of the structure and coupled to a shelf in close proximity. Before direct sunlight measurement, illumination values were obtained by placing the spectrometer in close proximity to each diffuser of the optical fiber and recording the value. This procedure was used on both $20 \mathrm{~mm}$ optical fibers within a time span of one minute. Lastly, a spectrometer was used to obtain direct sunlight illumination measurement on a clear sunny day on December 21, 2017, at 11:30 AM Greenwich Mean Time (GMT-5 in San Marcos, TX).

\section{Results}

3.1. Simulation Results. The correlation of the variation (CV) was collected from each height level from both end glow $6 \mathrm{~mm}$ and $20 \mathrm{~mm}$. CV measures the repeatability and reproducibility of the data. It is calculated using $\mathrm{CV}=$ (Standard Deviation $(\sigma) /$ Mean $(\mu)$ ) and is shown as a percentage. The lower the $\mathrm{CV}$, the greater the uniformity of the light distribution.

Figures 2 and 3 illustrate light distribution uniformity and intensity for different heights for $2 \times 3 \mathrm{~mm}$ and $20 \mathrm{~mm}$ fiber 


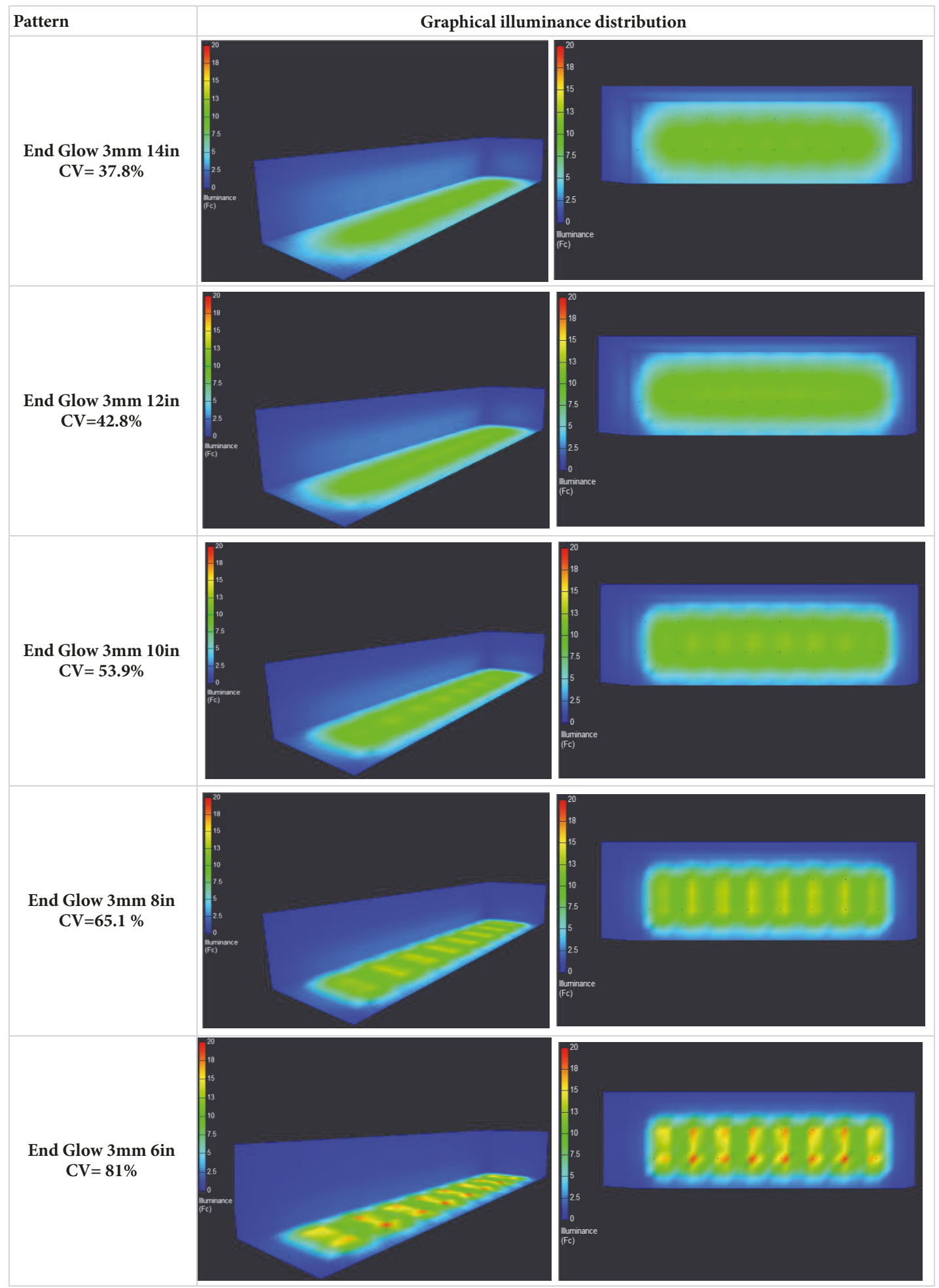

FIGURE 2: Results for the light distribution simulation for an end glow model $2 \times 3 \mathrm{~mm}$ cable.

optics cables, respectively. Figure 4 summarizes the CV for all simulation results for all five settings on both cables.

3.2. Empirical Results. For the empirical findings, light intensity was measured by the light spectrometer at $2 \mathrm{in}$. and
2.25 in. spacing for the $x$ and $y$ axes, respectively. Figure 5 shows the light intensity distributions for both cable types at different height settings. Figure 6 summarizes the entire empirical data collection. In this figure, the CV for both cable types are shown at different settings. 


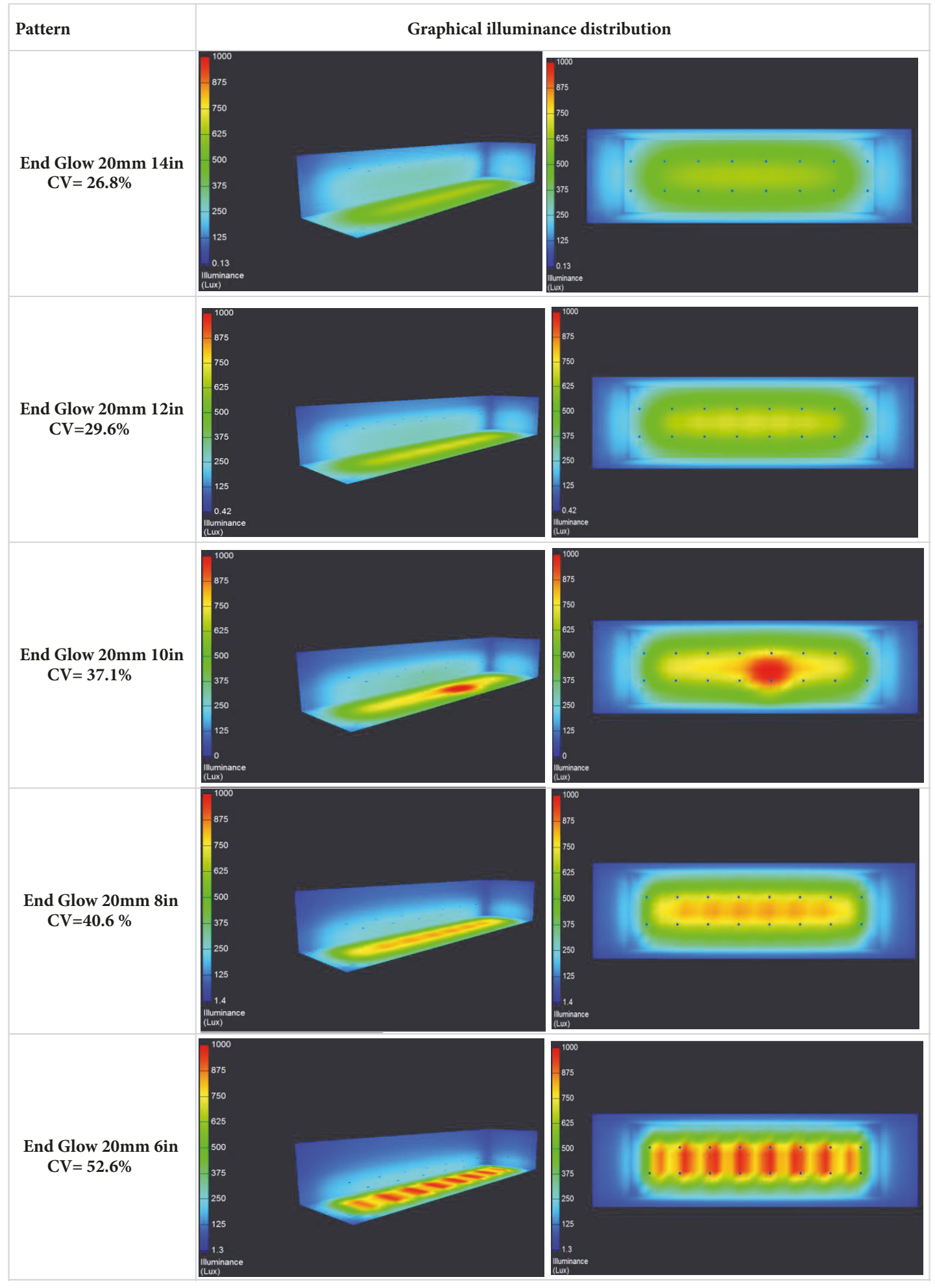

FIGURE 3: Results for the light distribution simulation for the end glow model $20 \mathrm{~mm}$ cable.

In this application, light distribution uniformity was not the most important factor as a uniform, but low, amount of light would not be useful. Figures 7 and 8 specifically demonstrate the light intensity ( $\mathrm{min}, \max$, and average) generated by the $20 \mathrm{~mm}$ and $2 \times 3 \mathrm{~mm}$ cables.
3.3. Natural Light Empirical Results. Table 1 provides information on the illumination values of direct sunlight, and the amount of that light that was transmitted through an optical fiber with and without an input UV filter. The quantum value of illumination was used to quantify the amount of 


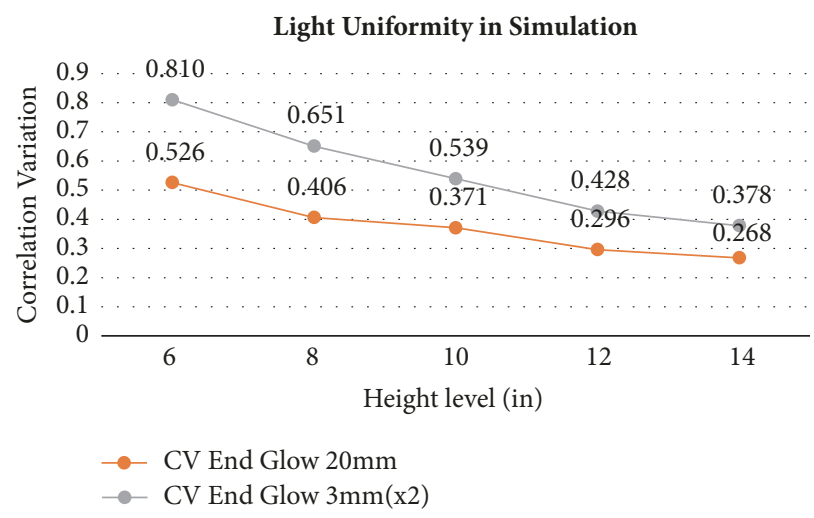

Figure 4: Correlation variation for the light distribution simulation for the end glow $20 \mathrm{~mm}$ and $2 \times 3 \mathrm{~mm}$.

TABLE 1: Illumination values of direct sunlight and $20 \mathrm{~mm}$ optical fiber with and without a filter in San Marcos, TX, at 11:30 AM GMT5 on December 21, 2017.

\begin{tabular}{lcc}
\hline \multirow{3}{*}{ Direct Sunlight } & \multicolumn{2}{c}{ Illumination (PPFD $\left.\left[\mathrm{umolm}^{-2} \mathrm{~s}^{-1}\right]\right)$} \\
& Optical Fiber & \\
& No Filter & Filter \\
\hline 2121 & 69.3 & 15.1 \\
\hline
\end{tabular}

radiation that would support indoor plant growth. The direct sunlight photosynthetic photon flux density (PPFD) was 2121. Radiation that measured the interior of the building at the end of the optical fiber with coupled diffuser with no filter gave a value of 69.3 PPFD. The recorded sunlight was 30 times greater than optical fiber with no filter. The optical fiber with a filter was illuminated at 15.1 PPFD, which was 140 times lower than direct sunlight and approximately 5 times lower than the optical fiber with no filter. Figures 9-11 depict the spectral values of all three measurement. Figures 10 and 11 show that the overall spectrum is very similar between the optical fiber with and without an UV filter. The main difference appears to be the lack of transmitted UV radiation below $400 \mathrm{~nm}$. Figures 9 and 10 show that the optical fiber with on UV filter absorbs/filters a large majority of the UV radiation near noon. Future research can measure the spectrum through the UV filter itself. This would tell us how effective the UV filter would be in protecting the polymer optical fiber from UV degradation.

As mentioned, the most effective and useful wavelength for plant photosynthesis is between $400 \mathrm{~nm}$ and $700 \mathrm{~nm}$. It is very promising that almost this entire wavelength range was transferred through the optical fiber (Figures 10 and $11)$.

\section{Conclusion and Discussion}

The simulation and empirical studies provided the following conclusions:

(i) Figures 4 and 6 show that, for both $20 \mathrm{~mm}$ and 2 $\times 3 \mathrm{~mm}$ fiber optics cables, an increase in distance between the light source and the measurement surface delivers more uniform light distribution (i.e., smaller CV).

(ii) While the simulation models (Figure 4) showed that $20 \mathrm{~mm}$ cables provide more uniform light distribution, the empirical study (Figure 6) demonstrates that the $2 \times 3 \mathrm{~mm}$ cables provide slightly more uniform light distribution than the $20 \mathrm{~mm}$ cables.

(iii) Although in practice the $2 \times 3 \mathrm{~mm}$ cables delivered and distributed slightly better light uniformity, Figures 7 and 8 show that the average amount of light delivered by the $20 \mathrm{~mm}$ cable was significantly more than the light delivered by the $2 \times 3 \mathrm{~mm}$ cables. For example, while the average light intensity for a $20 \mathrm{~mm}$ cable for all heights was above 50 Lux (Figure 7), the intensity of the light for the $2 \times 3 \mathrm{~mm}$ cables for all heights was less than 10 Lux (Figure 8).

(iv) Direct sunlight intensity is 140 times more than the light delivered through the optical cable. This method can be utilized as a free source of energy for indoor applications.

The discrepancy between the simulation and the actual empirical study seemed to be natural, as during the empirical measurement, we noticed that a small tilting angle of the end effector (crystal) with respect to the measuring equipment changes the light intensity reading significantly. Considering the flexibility of the cables and the continuous movement of the sun in real time practice, it is justified that, in daylighting optimization studies, trends rather than exact values should be considered and assessed.

The results of this study do not necessarily suggest the superiority of one cable size or one height over another. Different varieties of plants need different types of light intensity and distribution, and thus cables and height settings may be selected to best match the specific needs of a particular plant.

\section{Conflicts of Interest}

The authors declare that there are no conflicts of interest regarding the publication of this paper. 


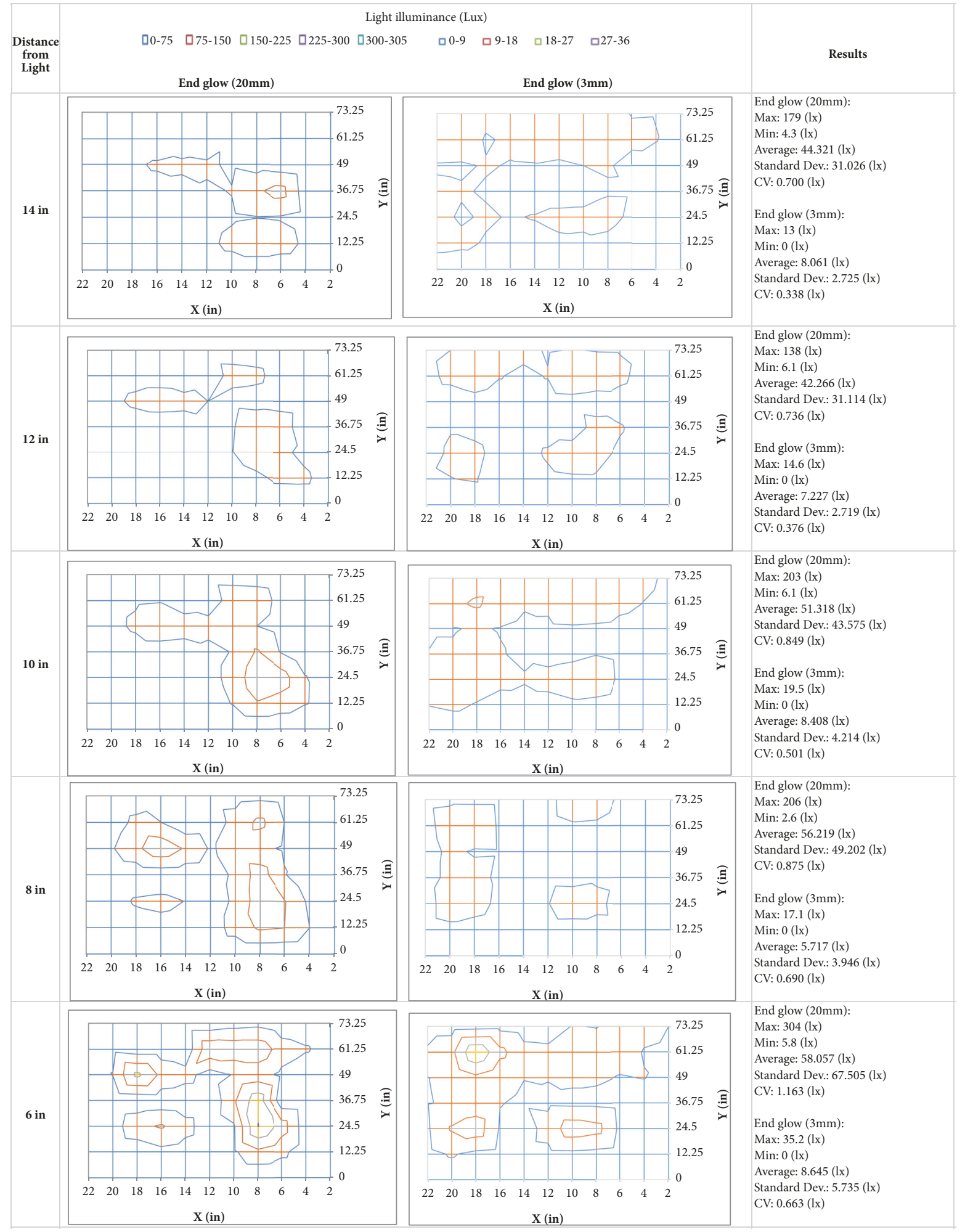

Figure 5: Light illumination for the end glow $20 \mathrm{~mm}$ and the end glow $2 \times 3 \mathrm{~mm}$.

\section{Acknowledgments}

This work was completed with funding from the US Department of Agriculture (Grant no. 2016-38422-25540) and the Department of Education-MSEIP program (Grant no.
P120A140065). The authors would like to thank the USDA, Department of Education, and Texas State University, for providing funding and access to both infrastructure and laboratories. The sponsors are not responsible for the content and accuracy of this article. 


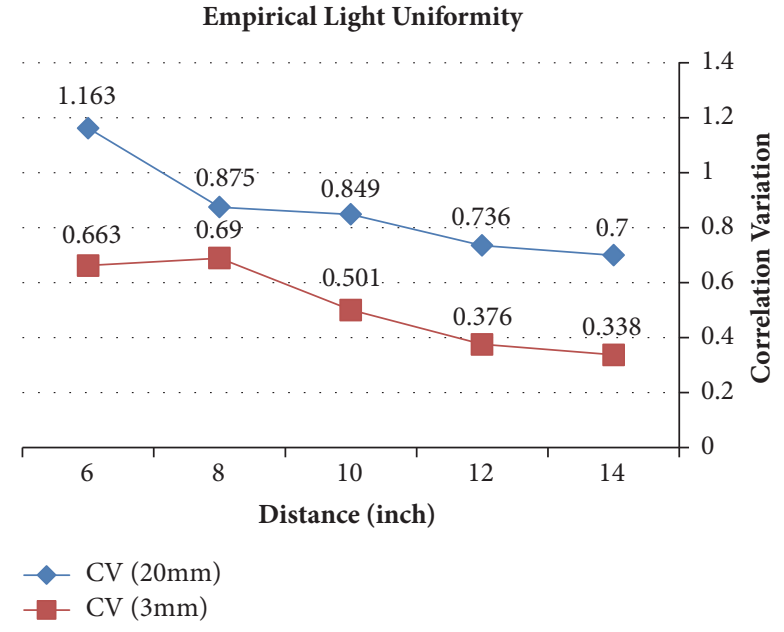

FIGURE 6: Correlation variation for the $20 \mathrm{~mm}$ and the $2 \times 3 \mathrm{~mm}$ end glow in empirical measurement.

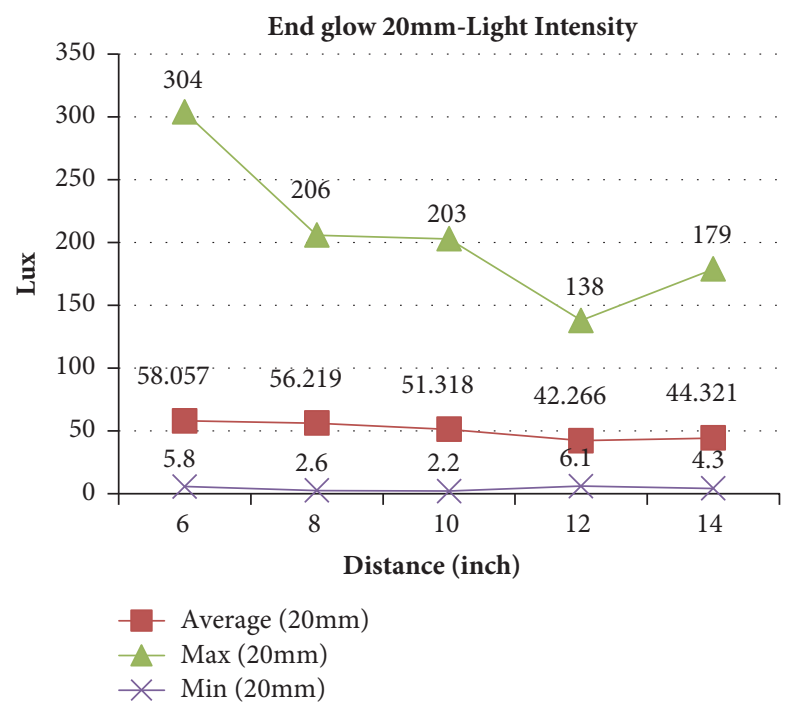

FIGURE 7: The average, max, and min of the measured light intensity at different heights for the $20 \mathrm{~mm}$ end glow cable.

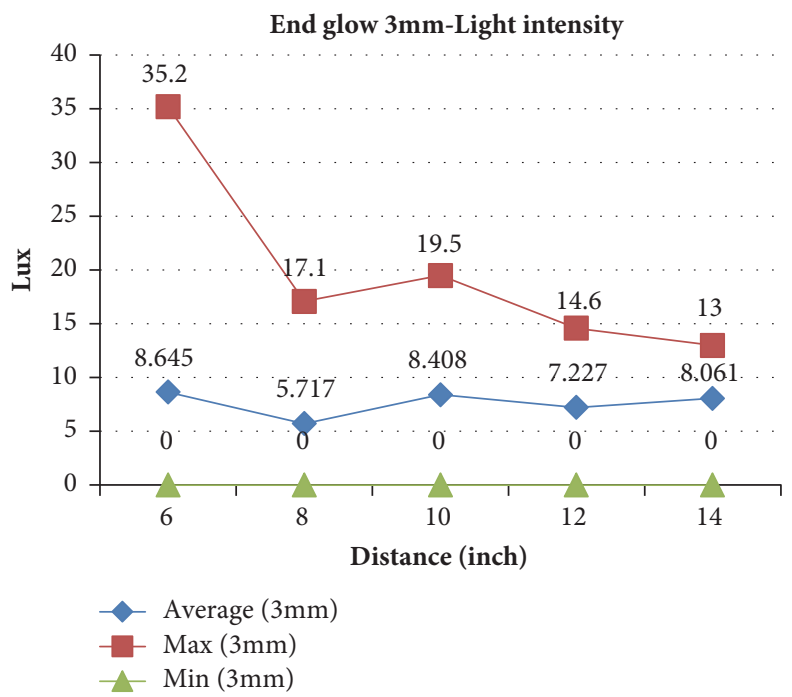

FIgURE 8: Average, max, and min of measured light intensity at different heights for the $2 \times 3 \mathrm{~mm}$ end glow cable. 


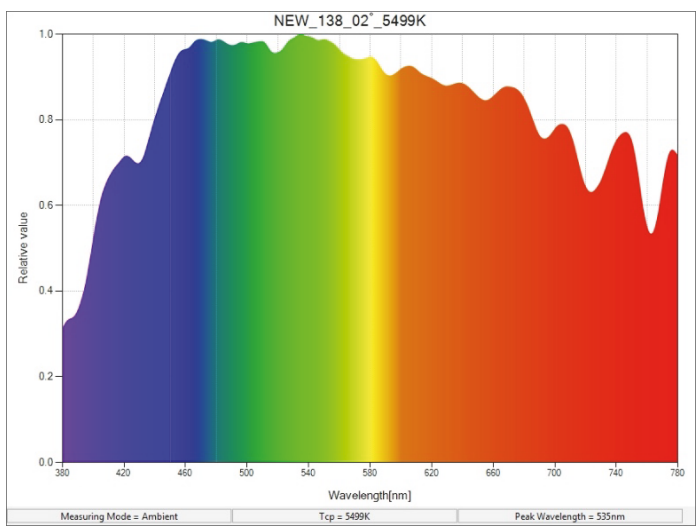

FIGURE 9: Direct sunlight spectrum.

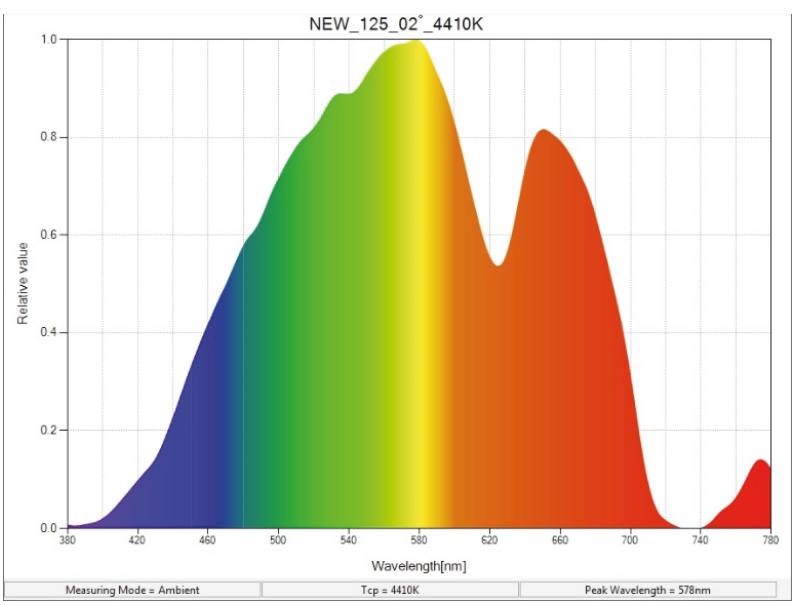

FIGURE 10: Optical fiber with filter spectrum.

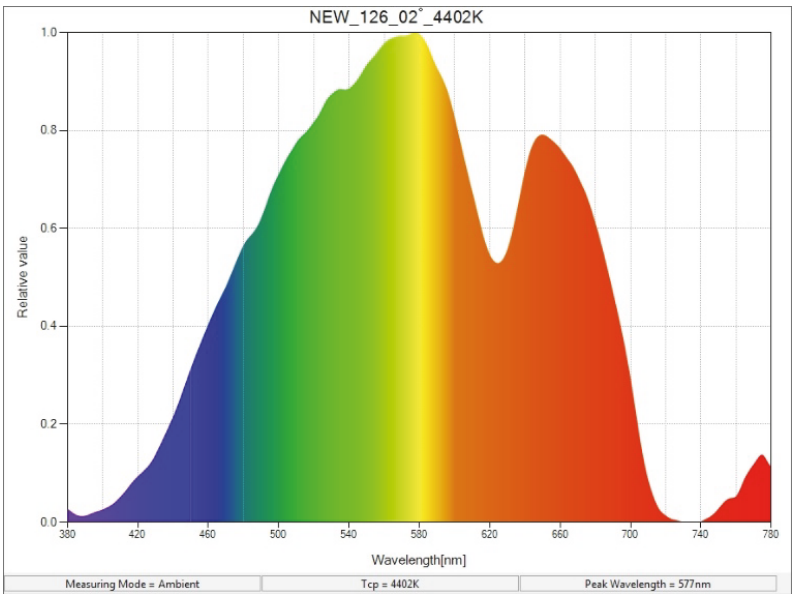

FIGURE 11: Optical fiber without filter spectrum.

\section{References}

[1] United States Census Breau. (n.d.), https://www.census.gov/ popclock/from.

[2] P. V. Mendez, "Study of the sustainability issues of food production using vertical farm methods in an urban environment within the state of indiana," Available from ProQuest Dissertations Theses Global, 2014.

[3] J. A. Foley, N. Ramankutty, K. A. Brauman et al., "Solutions for a cultivated planet," Nature, vol. 478, no. 7369, pp. 337-342, 2011. 
[4] J. Eaves and S. Eaves, "Comparing the Profitability of a Greenhouse to a Vertical Farm in Quebec," Canadian Journal of Agricultural Economics, vol. 66, no. 1, pp. 43-54, 2018.

[5] I. Ullah and A. J. W. Whang, "Development of Optical FiberBased Daylighting System and Its Comparison," Energies, vol. 8, no. 7, pp. 7185-7201, 2015.

[6] Agrilyst (2016), "State of Indoor Farming," http://www.dem.ri .gov/programs/agriculture/documents/stateofindoorfarmingreport-2016.pdf.

[7] J. Dae Ho, L. Joon Woo, K. Woo Hyun, H. In Ha, and S. Jung Eek, "Estimation of Whole Plant Photosynthetic Rate of Irwin Mango under Artificial and Natural Lights Using a ThreeDimensional Plant Model and Ray-Tracing," International Journal of Molecular Sciences, vol. 19, no. 1, pp. 1-14, 2018.

[8] I. L. Wong, "A review of daylighting design and implementation in buildings," Renewable \& Sustainable Energy Reviews, vol. 74, pp. 959-968, 2017.

[9] M. Mayhoub, “Innovative daylighting systems' challenges: A critical study," Energy and Buildings, vol. 80, pp. 394-405, 2014.

[10] K. Vasilakopoulou, D. Kolokotsa, M. Santamouris, I. Kousis, H. Asproulias, and I. Giannarakis, "Analysis of the experimental performance of light pipes," Energy and Buildings, vol. 151, pp. 242-249, 2017.

[11] H. Poisel, K. Hofbeck, M. Bloos, M. Lippenberger, S. Schutz, and A. Kist, "Solleckor, progess in fiber optic daylighting," in Proceedings of the SPIE - The International Society for Optical Engineering, Volume 8485, p. 8, 2012.

[12] T. Li and C. Yuan, "An optimal design analysis of a novel parabolic trough lighting and thermal system," International Journal Of Energy Research, vol. 40, no. 9, pp. 1193-1206, 2016.

[13] Echy: Natural Light with Fiber Optics, http://www.echy.fr/? lang=en.

[14] Parans Solar Lighting System (2016), http://www.wascoskylights.com/product/parans-solar-lighting-system/.

[15] Sollektor - Tageslicht für drinnen (Daylight for Indoor) (n.d.), https://www.wohnnet.at/wohnen/licht-schatten/sollektor-23231 .n.d.

[16] P. Kröplin, C. Dieling, M. Beckers et al., "11 - Overview of the POF market," Polymer Optical Fibres, pp. 349-400, 2017.

[17] Y. Koike and M. Asai, "The future of plastic optical fiber," NPG Asia Materials, vol. 1, no. 1, pp. 22-28, 2009.

[18] A. F. Garito, J. Wang, and R. Gao, "Effects of random perturbations in plastic optical fibers," Science, vol. 281, no. 5379, pp. 962-967, 1998.

[19] R. Ishikawa, L. Heeyoung, L. Amedee et al., "Perfluorinated graded-index plastic optical fiber Bragg gratings: Observation and theoretical analysis of unique dependence on pressure," in Microoptics Conference (MOC), pp. 224-225, IEEE, Tokyo, Japan, 19-22 Nov 2017.

[20] L. Yanhua, Y. Binbin, Z. Qijin, P. Gang-Ding, W. Jianxiang, and Z. Jianzhong, "Fabrication of Polymer Optical Fibre (POF) Gratings," Sensors, vol. 17, no. 3, 2017.

[21] G. Numata, N. Hayashi, M. Tabaru, Y. Mizuno, and K. Nakamura, "Ultra-Sensitive Strain and Temperature Sensing Based on Modal Interference in Perfluorinated Polymer Optical Fibers," IEEE Photonics Journal, vol. 6, no. 2, 2014.

[22] T. Awetehagn, S. M. Shitote, and O. Walter, "Experimental Evaluation on Light Transmittance Performance of Translucent Concrete," International Journal of Applied Engineering Research, vol. 13, 2018.
[23] K. J. McCree, "The action spectrum, absorptance and quantum yield of photosynthesis in crop plants," Agricultural and Forest Meteorology, vol. 9, no. C, pp. 191-216, 1971.

[24] AGI32, https://lightinganalysts.com/.

[25] B. Asiabanpour, R. Cano, L. Vanwagner, T. McCormick, and F. Wasik, "New design for conserving polymer powder for the SIS rapid prototyping process," in Proceedings of the 16th Solid Freeform Fabrication Symposium, SFF 2005, pp. 86-97, USA, August 2005.

[26] B. Asiabanpour, R. Cano, C. Subbareddy, F. Wasik, L. Vanwagner, and T. McCormick, "A new heater design by radiation modeling and a new polymer waste-saving mechanism design for the SIS process," Rapid Prototyping Journal, vol. 13, no. 3, pp. 136-147, 2007.

[27] B. Asiabanpour, C. Subbareddy, S. Kolichala, and L. Vanwagner, "Computer-aided energy and material savings for the SIS process," Society of Manufacturing Engineers/North American Manufacturing Research Institution (SME/NAMRI) Transaction, vol. 35, pp. 465-471, 2007. 

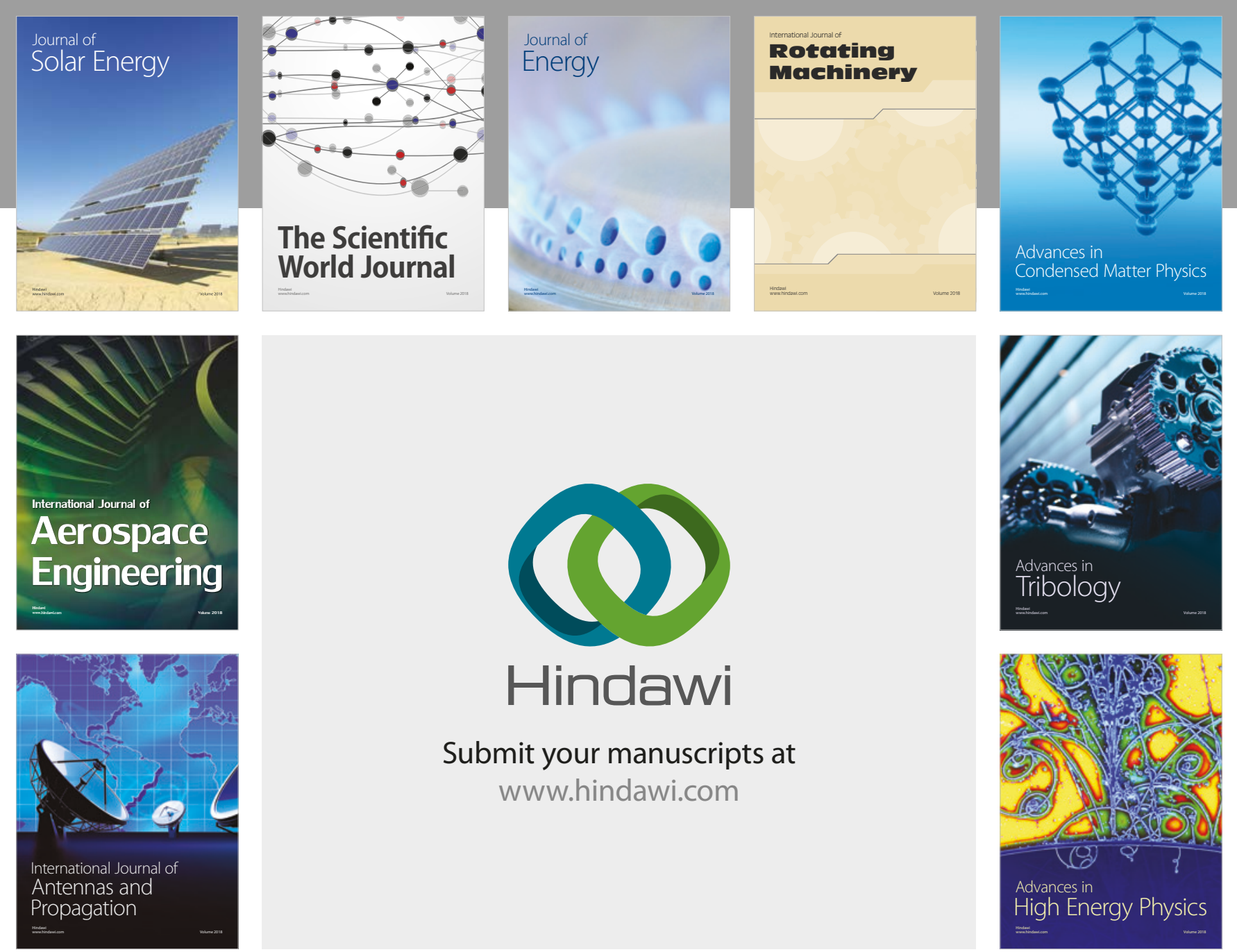

Submit your manuscripts at

www.hindawi.com
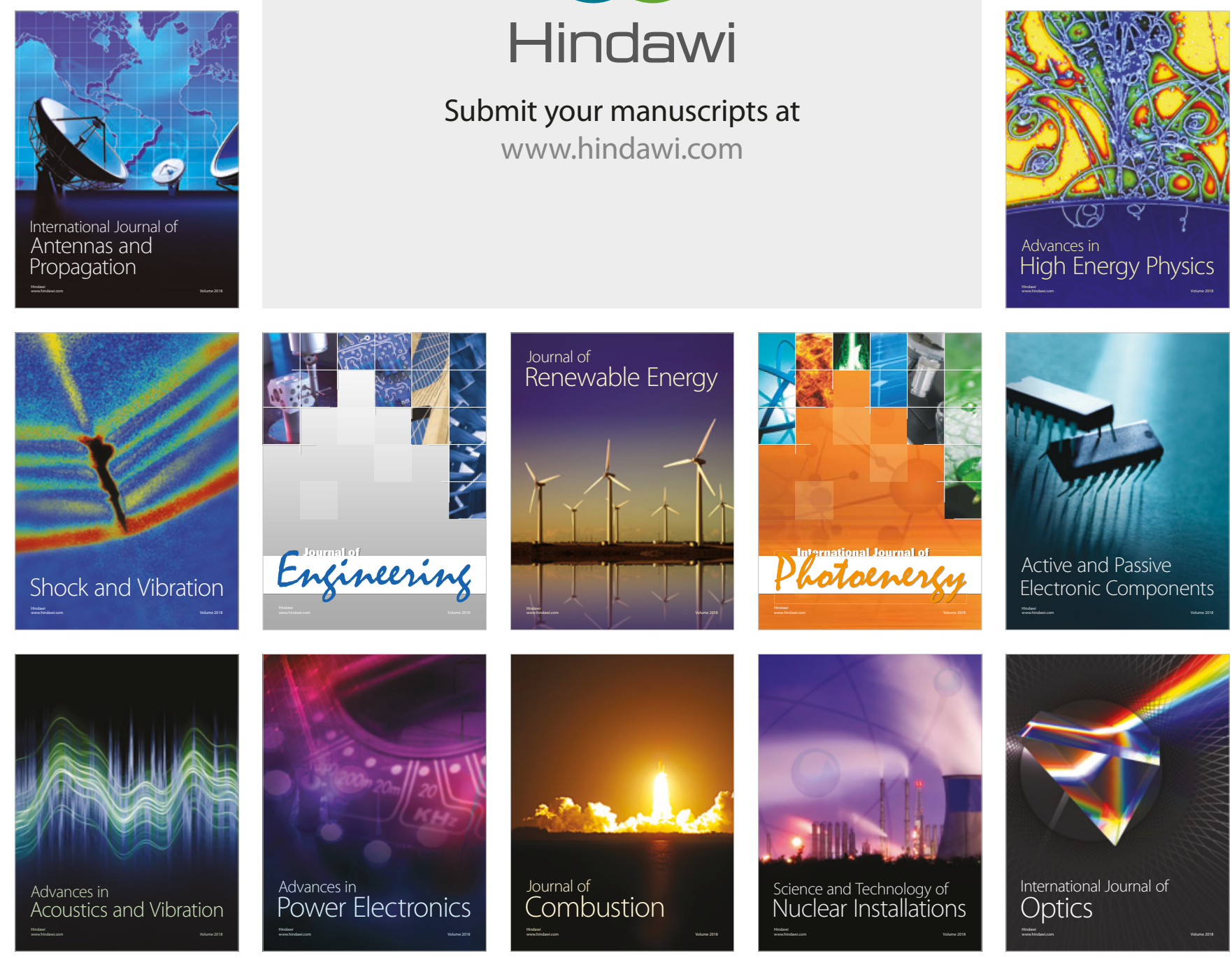